\title{
Professional attitudes in the UK towards neuroleptic maintenance therapy in schizophrenia
}

\author{
The problem of inadequate prophylaxis
}

\author{
D. A. W. Johnson and J. G. C. Rasmussen
}

\begin{abstract}
Controlled trials show that about $80 \%$ of schizophrenic patients remain relapse tree when given adequate neuroleptic maintenance therapy but this level of efficacy is not achieved in clinical practice. Guidelines for proper use of neuroleptics in relapse prevention were developed by a group of experienced psychiatrists - the 'Consensus Group' - in 1989. In this survey, the views of UK psychiatrists, GPs, CPNs and pharmacists involved in community care of schizophrenia were compared with the Guidelines.

A substantial proportion of respondents suggested shorter periods of neuroleptic maintenance than recommended and large regional variations were apparent. The results suggest that there remains substantia professional fallure to follow present guidelines or to assure adequate neuroleptic prophylaxis for schizophrenia.
\end{abstract}

Notwithstanding more than 40 years' study and clinical experience demonstrating conclusively the efficacy of neuroleptics in acute psychosis and relapse prevention, the rate of relapse among schizophrenic patients remains much higher than controlled studies predict (Kissling, 1992).

More than half (57\%) of first-episode patients (Crow et al, 1986) and three-quarters (74\%) of multi-episode patients (Kissling, 1992) will relapse within a year, while about $80 \%$ will remain relapse-free if adequate neuroleptic maintenance is given. Kissling (1992) suggests that the predominant reason for the failure to achieve this level of success in practice is non-compliance on the part of both patients and their doctors. He has estimated that application of the Guidelines in $80 \%$ of cases could reduce the incidence of relapse by nearly half. Surveys have already identified unsatisfactory changes in the way some clinicians prescribe depot neuroleptics (Johnson \& Wright, 1990).
Consequently, we decided to poll professionals involved in the care of schizophrenic patients to estimate the degree of professional compliance with the Guidelines put forward by the Consensus Group.

\section{The study}

Eighteen psychiatric consultants, three in each of the six major regions of the United Kingdom (South, Wales, Midlands, North, Scotland and Northern Ireland), agreed to host an evening teleconference the costs of which were underwritten by Lundbeck Ltd. Subsequently, all identifiable GPs, pharmacists and community psychiatric nurses (CPNs) in the area were invited by mail to attend this teleconference, which was generally to be held in the postgraduate centres at the consultant's hospital. The mailing explained the general purpose of the meetings but there was no specific inducement to attend.

On the evening of the conference, all sites were linked by telephone and the purpose explained in detail. Questions could be raised to clarify points of confusion. The telephone link was then broken and a simple form was distributed to collect the data.

Each participant was asked how long they would recommend a schizophrenic patient should remain on neuroleptic maintenance therapy under three different conditions which corresponded to the three recommendations put forward by the Consensus Group (Kissling, 1992):

(a) Patients following response to acute treatment of their first episode (first-episode patients) 
(b) Patients following response to acute treatment of their second or further episode (multi-episode patients)

(c) Patients suspected or with a history of suicidal or violent behaviour (aggressive patients)

Responses, identified only by site and speciality, were collected by post, entered into a computer, stratified and tabulated.

\section{Findings}

Fifty-five consultant psychiatrists responded, or about $10 \%$ of those practising in the UK. The results have been collapsed to correspond roughly to the intervals recommended by the Consensus Group.

Table 1 stratifies results by speciality. Considering first-episode patients, about half of prescribers and two-thirds of CPNs and pharmacists fail to meet the minimum Guideline. For multi-episode patients, most prescribers would conform to the minimum recommendation but less than half would persist with treatment. The pattern is similar when violent or suicidal patients are considered but with greater consensus across the groups.

Regional differences are apparent and are in some cases striking (Table 2). However, there is no evidence that schizophrenia or its prognosis differs from one region to another to justify such differences in basic therapy as suggested by our data. Although the nature of the care-delivery team and even its key personnel may have to vary in accord with regional requirements, the basic medical and social services provided should be very similar.

\section{Comment}

Schizophrenia in the great majority of patients is a life-long condition. Psychosocial therapy, care in the community as well as hope of a normal life for these patients all depend upon effective neuroleptic control of florid symptoms. This was recognised in specific recommendations of the Consensus Group (Kissling et al, 1991).

"As it is not possible to identify the small group of survivors [patients who will not relapse] in advance. and in view of the potentially devastating consequences of a schizophrenic relapse, neuroleptic treatment is probably advisable for virtually all patients suffering from schizophrenia. The only exceptions are possibly those patients for whom the side-effects of the medication are more severe than the potential consequences of relapse, rare individuals with very mild psychotic episodes, and patients for whom the psychiatric diagnosis is questionable."

More specifically, they recommended:

"The suggested recommendations of the group for first-episode patients was that they should be offered at least 1-2 years of maintenance neuroleptic treatment."

"The group agreed that multi-episode patients should receive neuroleptic maintenance treatment for at least 5 years."

"For patients with a history of suicide attempts or violent. aggressive behaviour, maintenance treatment with neuroleptics may be indicated for longer than 5 years and perhaps indefinitely."

The Consensus Group clearly felt that drug therapy should be continued in many cases beyond their recommended periods as the risk of relapse remains high (Kissling et al, 1991). This view has been emphasised by Davis et al

Table 1. Respondents' recommendations by speciality for duration of neuroleptic maintenance for first-episode, multi-episode and suicidal/violent patients

\begin{tabular}{lcclll}
\hline & $\begin{array}{l}\text { Psychiatrists } \\
(n=55) \\
\%\end{array}$ & $\begin{array}{l}\text { GPs } \\
(n=29) \\
\%\end{array}$ & $\begin{array}{l}\text { Pharmacists } \\
(n=47) \\
\%\end{array}$ & $\begin{array}{l}\text { CPNs } \\
(n=33) \\
\%\end{array}$ & $\begin{array}{l}\text { Overall } \\
(n=164) \\
\%\end{array}$ \\
\hline $\begin{array}{l}\text { First-episode patients } \\
\text { Up to 12 months }\end{array}$ & 41.8 & 48.3 & 40.4 & 54.5 & 45.1 \\
1-2 years or more & 54.5 & 44.8 & 29.8 & 33.3 & 41.5 \\
N/A' & 3.6 & 6.9 & 29.8 & 12.1 & 13.4 \\
Multi-episode patients & & & & & \\
Up to 1-2 years & 10.9 & 31 & 27.7 & 12.1 & 19.5 \\
3-5 years or more & 89.1 & 69 & 55.3 & 78.8 & 73.8 \\
N/A' & 0 & 0 & 17.0 & 9.1 & 6.7 \\
Suicidal or violent patients & & & & & \\
Up to 3-5 years & 20.0 & 24.1 & 23.4 & 21.2 & 22.0 \\
Indefinitely & 74.5 & 75.9 & 55.3 & 69.7 & 68.3 \\
N/A' & 5.5 & 0 & 21.3 & 9.1 & 9.8 \\
\hline
\end{tabular}

1. N/A="unknown" or "no response". 
Table 2. Respondents' recommendations by region for duration of neuroleptic maintenance for firstepisode, multi-episode and suicidal/violent patients

\begin{tabular}{|c|c|c|c|c|c|c|c|}
\hline & $\begin{array}{l}\text { South } \\
(n=51) \\
\%\end{array}$ & $\begin{array}{l}\text { Wales } \\
(n=16) \\
\%\end{array}$ & $\begin{array}{l}\text { Midlands } \\
(n=31) \\
\%\end{array}$ & $\begin{array}{l}\text { North } \\
(n=31) \\
\%\end{array}$ & $\begin{array}{l}\text { Scotland } \\
(n=12) \\
\%\end{array}$ & $\begin{array}{l}\text { N. Ireland } \\
(n=23) \\
\%\end{array}$ & $\begin{array}{l}\text { Overall } \\
(n=164) \\
\% 1\end{array}$ \\
\hline $\begin{array}{l}\text { First-episode patients } \\
\text { Up to } 1 \text { year } \\
1-2 \text { years \& more } \\
\text { N/A' }\end{array}$ & $\begin{array}{l}51 \\
37.3 \\
11.8\end{array}$ & $\begin{array}{l}50 \\
37.5 \\
12.5\end{array}$ & $\begin{array}{l}22.6 \\
58.1 \\
19.4\end{array}$ & $\begin{array}{l}32.3 \\
45.2 \\
22.6\end{array}$ & $\begin{array}{r}58.3 \\
33.3 \\
8.3\end{array}$ & $\begin{array}{c}69.6 \\
30.4 \\
0\end{array}$ & $\begin{array}{l}45.1 \\
41.5 \\
13.4\end{array}$ \\
\hline $\begin{array}{l}\text { Multi-episode patients } \\
\text { Up to } 2 \text { years } \\
3-5 \text { years \& more } \\
\text { N/A }\end{array}$ & $\begin{array}{r}19.6 \\
76.5 \\
3.9\end{array}$ & $\begin{array}{l}25 \\
62.5 \\
12.5\end{array}$ & $\begin{array}{r}6.5 \\
77.4 \\
16.1\end{array}$ & $\begin{array}{r}12.9 \\
80.6 \\
6.5\end{array}$ & $\begin{array}{r}50 \\
50 \\
0\end{array}$ & $\begin{array}{c}26.1 \\
73.9 \\
0\end{array}$ & $\begin{array}{r}19.5 \\
73.8 \\
6.7\end{array}$ \\
\hline $\begin{array}{l}\text { Suicidal or violent patients } \\
\text { Up to } 3-5 \text { years } \\
\text { Indefinitely } \\
\text { N/A' }\end{array}$ & $\begin{array}{r}19.6 \\
72.5 \\
7.8\end{array}$ & $\begin{array}{l}12.5 \\
75 \\
12.5\end{array}$ & $\begin{array}{l}22.6 \\
54.8 \\
22.6\end{array}$ & $\begin{array}{l}19.4 \\
71 \\
9.7\end{array}$ & $\begin{array}{c}33.3 \\
66.7 \\
0\end{array}$ & $\begin{array}{c}30.4 \\
69.6 \\
0\end{array}$ & $\begin{array}{l}22 \\
68.3 \\
9.8\end{array}$ \\
\hline
\end{tabular}

1. N/A="unknown" or "no response".

(1994) who criticised the Consensus Group for failure to extrapolate from the large body of existing information. Davis et al present compelling evidence that the rate of relapse following cessation of neuroleptic maintenance remains constant among survivors at about $10-15 \%$, month on month, for at least the first few years and probably longer. On this basis, they recommended that most schizophrenic patients should continue neuroleptic maintenance therapy indefinitely.

Failure to prescribe long-term, prophylactic neuroleptic therapy - what Kissling (1992) has called 'physician non-compliance' - places patients at risk of relapse and, as Johnson (1979) showed, at risk of higher cumulative exposure to neuroleptics. In a survey of 117 German psychiatrists, Kissling (1992) found only $20 \%$ would continue neuroleptic maintenance for at least two years after an acute first episode and only $11 \%$ would maintain prophylactic treatment for at least five years following two acute episodes within a single year. These results are not dissimilar to our own.

Patient non-compliance is a central problem in management of schizophrenia. Not only do patients fail to comply with their prescribed drug regimen but their doctors may fail to prescribe neuroleptic maintenance of adequate duration or dose. They also fail to convince their patients of the overall benefits of such therapy.

Non-compliance among schizophrenic patients is well documented (Goad \& Ezell, 1990; Putten et al, 1990; Hale, 1993) and affects 33-54\% of out-patients receiving oral medication (Hale, 1993). Davis et al (1994) suggest that, in the absence of positive evidence to the contrary, any acute schizophrenic relapse of a self-proclaimed, compliant patient should be taken prima facie as evidence of non-compliance. Consequently, they and others recommend that depot formulations should be the treatment of first choice for schizophrenic out-patients.

Because they bypass first-pass metabolism, depot formulations can offer reduced variation in plasma levels and, consequently, reduced variation in response to a given dose. Moreover, depot is the only route of administration which assures the clinician of the actual dose received by the patient, knowledge which is essential for all clinical decisions concerning management of the disease and adverse effects of treatment.

Considering the accumulated evidence, it must be of grave concern that just over half the psychiatrists and only a third of the CPNs in our survey thought maintenance therapy for first-episode patients should persist beyond one year. Moreover, differences among these professionals, who have the greatest influence on patient compliance, must be of equal concern. Patients are likely to receive conflicting advice from various professionals, perhaps even within the same treatment team.

Care in the community as well as the cost of care are both threatened by inadequate maintenance therapy or non-compliance. Boyd et al (1994) in the inquiry into homicide and suicide committed by mentally ill patients noted that non-compliance was a factor in 13 of 22 cases they reviewed. Although rare, these cases cause great private anguish and public anxiety. They threaten not only care in the community but also acceptance of mentally ill people in society. They also indicate a profound failure of care delivered to these few individuals and in all probability to the much larger group of patients who needlessly suffer acute relapse.

The superiority of depot formulations in prophylaxis is compelling (Johnson, 1976; Hale, 
1993; Boyd et al, 1994; Tylee, 1995). Such therapy is necessary in the great majority of schizophrenic patients even following the first. acute episode and must be virtually mandatory following any relapse or among potentially violent or suicidal patients. Any failure of a patient to attend for routine prophylactic treatment must be considered a potential emergency as evidence indicates that risk of relapse exists regardless of the duration of successful prophylaxis.

Following inquiries into recent homicides committed by schizophrenic patients, there have been recommendations that the legal framework for care in the community be altered to allow compulsory prophylactic medication for patients living in the community (BMJ News, 1995; BlomCooper et al, 1993). Clearly, this is in the best interest of the great majority and would clarify the responsibilities and authority of the clinical care team. It should also promote greater consistency of view toward prophylactic medication than we have seen in our data.

As acknowledged by the Consensus Group, in a very small minority of cases, the adverse effects of neuroleptic treatment may outweigh the consequences of relapse. Nevertheless, until such time as more benign but equally effective drugs are available or means are discovered to correct the underlying causes of schizophrenia. long-term use of depot neuroleptics appears to offer the best hope for the great majority of patients suffering from schizophrenia. Yet results of this survey indicate that many clinical treatment protocols fall substantially short of what research results and expert recommendations suggest.

\section{References}

BLOM-COOPER, L., MURPHY, E. \& HALLY, H. (1993) The Falling Shadow. One Patient's Mental Health Care, 1978-1993. Report of the Committee of Enquiry into the Events Leading up to, and Surrounding. the Fatal Incident at the Edith Morgan Centre, Torbay, Ist September, 1993. London: Duckworth.
BMJ NEws (1995) Mental health law obsolete, says inquiry. British Medical Journal, 310, 145-146.

BOYD, W., SimS, A. \& BROOKER, A. (1994) A Preliminary Report on Homicide. Steering Committee of the Confidential Inquiry into Homicides \& Sulcides by Mentally Ill People.

Crow, T. J., MCMiLAM, J. P., Johnson, A. L., et al (1986) The Northwick Park study of first eplsodes of schizophrenia: II. A randomised controlled trial of prophylactic neuroleptic treatment. British Journal of Psychiatry. 148. 120-127.

Davis, J. M.. Metalon, L., Watanabe, M. D.. et al (1994) Depot antipsychotic drugs: Place in therapy. Drugs, 47. 741-773.

GOAD, T. D., \& EzEL, T. R. (1990) Drug use evaluation programs for psychotropic medications. American Joumal of Hospital Pharmacy. 47, 132-136.

HALE, A. (1993) Will the new antipsychotics improve the treatment of schizophrenia? Depot preparations still hold the key to compliance. British Medical Journal. 307, 249-250.

Johnson. D. A. W. (1976) The expectation of outcome for maintenance therapy in schizophrenia. British Journal of Psychiatry. 128, 246-250.

- (1979) Further observations on the duration of depot neuroleptic maintenance therapy in schizophrenia. British Joumal of Psychiatry. 136. 524-530.

- \& WRIGHT, W. (1990) Drug prescribing to schizophrenic outpatients on depot injections: Repeat surveys over 18 years. Britsh Journal of Psychiatry, 166, 822-834.

KissuNG. W. (1992) Ideal and reality of neuroleptic relapse prevention. Brtish Journal of Psychiatry, 161 (suppl. 18), 133-139.

-. KANE, J. M., BARNES, S. J., et al (1991) Guidelines for neuroleptic relapse prevention in schizophrenia: Towards a consensus vlew. In Schizophrenia led. W. W. Kissling). pp. 155-163. Berlin: Springer-Verlag.

Putten, T. VAN, Morden, S. P. \& Wissheng, W. C. (1990) Surreptitious non-compliance with oral fluphenazine in a voluntary inpatient population. Archives of General Psychiatry, 47, 786-787.

ThLE. A. (1995) Drug treatment for schizophrenia. The Practitioner, 239. 116-119.

D. A. W. Johnson, Hon. Consultant, South Manchester University Hospitals (NHS) Trust, c/o 14 St John's Street, Manchester M3 4DZ; and *J. G. C. Rasmussen, Leacroft Medical Practice, Leacroft, Ifield Road, West Green, Crawley, West Sussex RH117BS

*Correspondence 